\title{
APPLICATION OF ADJOINT CMAQ CHEMICAL TRANSPORT MODEL IN THE ATHENS GREATER AREA: SENSITIVITIES STUDY ON OZONE CONCENTRATIONS
}

\author{
Spyros Andronopoulos, Athanasios Sfetsos, Diamando Vlachogiannis, Andreas Yiotis and Nikolaos Gounaris \\ Environmental Research Laboratory, Institute of Nuclear Technology - Radiation Protection, \\ NCSR "DEMOKRITOS", 15310 Aghia Paraskevi Attikis, Athens, Greece
}

\begin{abstract}
An operational meteorology and air quality forecasting system is currently under development by the Environmental Research Laboratory of NCSR "Demokritos". The system is based on the meteorological model MM5, the in-house EMISLAB emissions processing system and the chemical transport model CMAQ. It is configured to apply on the Greater Athens Area with a 4-domains nested configuration focusing on a high spatial resolution $\left(1 \times 1 \mathrm{~km}^{2}\right)$ inner domain. The system produces meteorological and air quality predictions for a 72-hours time horizon with 1 hour time step. This paper uses the output of the operational system to apply the CMAQ adjoint for ozone sensitivity calculations, focusing for the two days of 18 and 19 July 2005.

In the current study, the calculated ground level ozone concentrations at certain defined locations and times are considered as the "response functional". Sensitivities of the response functional with respect to the state variables (species concentrations on the grid points and species emissions, e.g., $\mathrm{NO}_{\mathrm{x}}, \mathrm{CO}, \mathrm{VOCs}$ ) are calculated by running the adjoint model backwards in time (reverse mode). The distribution of the sensitivities in the computational domain, obtained for different times, provides essential information for the analysis: isosurfaces of sensitivities delineate influence regions, i.e., areas where perturbations in some concentrations will result in significant changes in the ozone concentrations in the area of interest at the final time.
\end{abstract}

Key words: Adjoint model, sensitivity analysis, ozone.

\section{INTRODUCTION}

Air quality models are important tools in air quality management and policy making for regulatory purposes. To evaluate the effectiveness of such decisions in air quality, sensitivity analysis is often undertaken for diagnostic and prognostic calculations. The usual approach in the sensitivity analysis is the forward mode in which, any perturbation in one or more input variables (e.g. initial conditions, emissions) is carried forward in time resulting in the calculation of derivatives at multiple receptors with respect to the perturbed initial and/or model parameters (Hakami et al., 2003). In adjoint (backward) mode, a perturbation in a receptor based metric is propagated backward in time resulting in the calculation of its sensitivities with respect to a large number of perturbed input parameters (Cacuci and Ionescu-Bujor, 2005). The mathematical formulation of the adjoint sensitivity for nonlinear dynamical systems has been presented by Cacuci (1981a, 1981b) and Marchuk et al. (1996). As the adjoint sensitivity method is a potent tool with a strong potential for diverse applications, it has attracted the attention of the atmospheric modellers in the recent years. The mathematical description of the adjoint sensitivity method applied to air transport and chemical models, presenting at the same time a complete set of computational tools for performing three-dimensional adjoint sensitivity studies can be found in Sandu et al. (2005).

The adjoint sensitivity method in air quality models results in a more accurate simulation of the spatial and temporal 3-dimansional fields of the chemical constituents in relation to their sources and sinks. In addition, the adjoint technique can integrate efficiently observational data into the model following a 4-dimensional variational (4D-Var) data assimilation process (Sandu et al., 2005). The method of 4D-Var data assimilation was applied to the analysis of chemically active trace species for the first time, using a Lagrangian stratospheric model, by Fisher and Lary (1995). Elbern and Schmidt (1999) presented the first adjoint of a 3-D Eulerian Chemistry Transport Model (CTM) to include chemistry. In Elbern et al., (2000) a study was presented of the advantages and limits of the 4D-var technique to analyze the emission rates of non-observed precursor constituents of ozone, when only ozone observations are available. A review of the theoretical formulation of the adjoint method in 4D atmospheric chemistry data assimilation was performed by Wang et al. (2001).

These initial works have been followed more recently by similar development and application of adjoint models of several CTMs: e.g. CHIMERE (e.g. Schmidt and Martin, 2003), IMAGES (e.g. Stavrakou and Muller, 2006), the California Institute of Technology urban-scale model (e.g. Martien and Harley, 2006) and DRAIS (Nester and Panitz, 2006). The adjoint of the regional model STEM has also been developed (Sandu et al., 2005) and deployed (Hakami et al., 2006; Chai et al., 2006). Henze and Seinfeld (2006) applied the adjoint of the global chemical transport model GEOS-Chem, focusing on the chemical and thermodynamic relationships between sulfate - ammonium - nitrate aerosols and their gas-phase precursors. Zhang et al., (2008) have performed adjoint sensitivity analysis and 4D-Var data assimilation to investigate the maximum area of influence within the atmosphere on ozone concentrations, using STEM (Sulfur Transport Eulerian Model) over the state of Texas.

\section{MODEL CONFIGURATION}

This paper presents an attempt to improve our understanding of ozone in the Greater Athens Area (GAA) by performing an adjoint sensitivity analysis at ground level ozone concentrations, in July $18 \& 19,2005$. The adjoint version of the Community Multiscale Air Quality, (CMAQ v.4.5), a 3-D atmospheric dispersion and photochemical model, has been employed to conduct the sensitivity analysis. The meteorological predictions are produced by the 
MM5 (Mesoscale Model 5) (Penn State University version 3.7.2), which has been parameterized for application to the particular geographical and climatic characteristics of the GAA. Its output is used to produce high resolution daily air emissions inventories for the main anthropogenic and biogenic pollutants with 1-hour time step by an in-house built processor named EMISLAB. The meteorological prediction fields in combination with the emissions inventories are used as inputs to the CMAQ model.

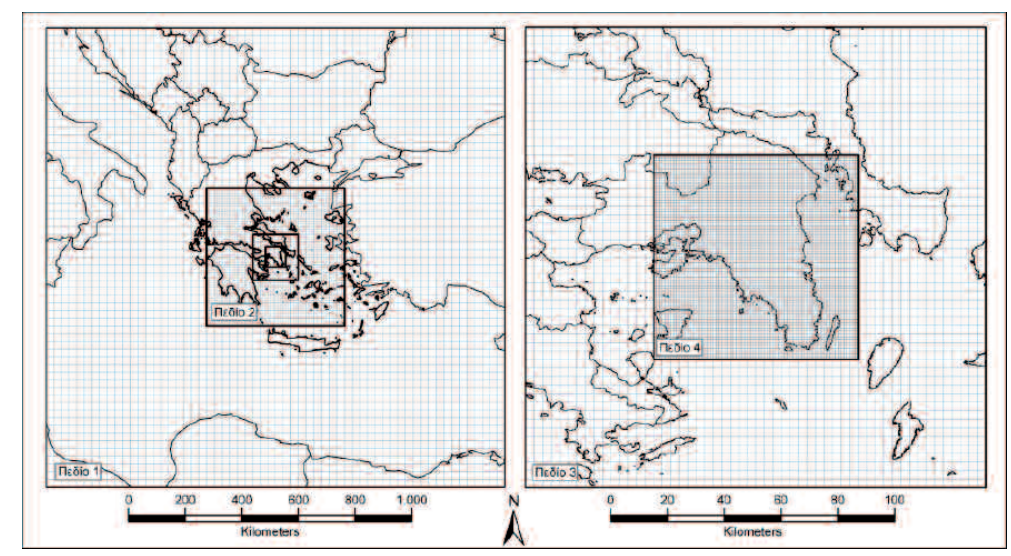

Figure 1. Working Domain specifications.

Table 1. Domain characteristics.

\begin{tabular}{|c|c|c|}
\hline & Cells & $\begin{array}{c}\text { Cell } \\
\text { size }(\mathrm{km})\end{array}$ \\
\hline Domain 1 & $60 \times 60$ & $27 \times 27$ \\
\hline Domain 2 & $54 \times 54$ & $9 \times 9$ \\
\hline Domain 3 & $54 \times 54$ & $3 \times 3$ \\
\hline Domain 4 & $72 \times 72$ & $1 \times 1$ \\
\hline
\end{tabular}

\section{ADJOINT CALCULATIONS}

Two consecutive days have been selected in order to study the combined meteorology and chemistry effects on the concentration of $\mathrm{O} 3$ in two selected locations in the Greater Athens Area. Two stations have been selected for the analysis which according to the annual report of the Ministry of the Environment exhibit the highest amount of episodic events (i.e. exceedances of maximum 8-h average value) on an annual basis: Thrakomakedones and Agia Paraskevi (location of NCSRD).

\section{JULY 18, 2005}

This day is characterized by $\mathrm{N}-\mathrm{NW}$ surface winds as predicted by the meteorological model MM5. The concentrations that influence the O3 value at 12:00 GMT on the Thrakomakedones area are located on the N-NW part of the area, and more specifically on the industrial zone between neighbouring prefects of Attiki and Biotia. (Fig. 2 and Fig. 3)

\section{JULY 19, 2005}

This day is characterized by wind breeze conditions as predicted by the meteorological model MM5. The morning low/moderate wind speeds blowing from the NW direction demonstrate a shift due to sea-land temperature differences in the late morning and afternoon hours from the sea towards inland. The concentrations that influence the $\mathrm{O}_{3}$ value at 12:00 GMT on the Agia Paraskevi area are diverse and vary according to the strength of the emissions, the meteorological fields and the complex topography of the area.

Figure $4 \mathrm{~d}$ shows the variation of $\mathrm{O} 3$ at 12:00 GMT on the receptor location with respect to $\mathrm{O}_{3}$ concentration on a 3-h interval backwards in time, which is related mainly to transport. It is important to note the transport of $\mathrm{O} 3$ from the sea (both south and east of the receptor). The main emissions are from the city centre, predominately traffic, the Athens International Airport and shipping portrayed in Figure 5 for the $\mathrm{NO}_{\mathrm{X}}$.

\section{CONCLUSIONS}

This paper presented the ozone sensitivity analysis for the Greater Athens Area performed using the adjoint version of CMAQ. The adjoint CMAQ estimates the sensitivity of ozone concentrations on user defined locations (receptors) and temporal. Adjoint sensitivity analysis allows us to assess the areas that have the largest impact on a given receptor site. For the purposes of this study two receptor locations were selected on two days with different meteorological conditions. The difference on the areas of influence is evident depending on the prevailing wind field. 
Concerning the day with wind breeze conditions that correspond to high O3 levels in the GAA, the impact of the large emissions sources can be easily traced (city center / traffic, airport and shipping emissions)

\section{REFERENCES}

Cacuci D.G, 1981a: Sensitivity theory for nonlinear systems. I. Nonlinear functional analysis approach. J. Math. Phys., 22, 2794-2802.

Cacuci, D.G, 1981b: Sensitivity theory for nonlinear systems. II. Extensions to additional classes of responses, $J$. Math. Phys., 22, 2803-2812.

Cacuci, D.G. and M. Ionescu-Bujor, 2005: Deterministic local sensitivity analysis of augmented systems - I: Theory. Nucl. Sci Engin., 151, 55-66.

Chai, T.F, G.R. Carmichael, A. Sandu, Y.H. Tang and D.N. Daescu, 2006: Chemical data assimilation of Transport and Chemical Evolution over the Pacific (TRACE-P) aircraft measurements. J. Geophys. Res., 111, D02301, doi:10.1029/2005JD005883.

Elbern, H,H. Schmidt, O. Talagrand and A. Ebel, 2000: 4D-variational data assimilation with an adjoint air quality model for emission analysis. Envir.1 Modeling and Software, 15, 539-548.

Elbern, H. and H. Schmidt, 1999: A four-dimensional variational chemistry data assimilations scheme for Eulerian chemistry transport modelling. J. Geophys. Res., 104, 18583-18598.

Fisher, M. and D.J. Lary, 1995: Lagrangian four-dimensional variational data assimilation of chemical species. Quart. J. - Royal Met. Society, 121, Issue 527, 1681-1704.

Hakami, A,J. H. Seinfeld, T. Chai, Y. Tang, G.R. Carmichael and A. Sandu, 2006: Adjoint Sensitivity Analysis of Ozone Non-attainment over the Continental United States. Environ. Sci. Technol., 40 (12), 3855 -3864.

Hakami, A, M.T. Odman and A.G. Russell, 2003: High-order, direct sensitivity analysis of multidimensional air quality models. Environ. Sci. Technol., 37, 2442.

Henze, D.K. and J.H. Seinfeld, 2006: Development of the adjoint of GEOS-Chem. Atmos. Chem. Phys. Discuss., 6, 10591-10648.

Kumaresh, S, A. Sandu, A. Hakami and J. Seinfeld, 2007: CMAQ v4.5 Adjoint User's Manual, electronic supplement of the report submitted to Houston Research Council, H59.

Marchuk, G.I, P.V. Agoshkov and I.V. Shutyaev, 1996: Adjoint Equations and Perturbation Algorithms in Nonlinear Problems, CRC Press, New York, 1996.

Martien, P.T. and R.A. Harley, 2006: Adjoint sensitivity analysis for a three-dimensional photochemical model: Application to Southern California. Environ. Sci. Technol., 40, 4200-4210.

Nester, K. and H.J Panitz, 2006: Sensitivity analysis by the adjoint chemistry transport model DRAIS for an episode in the Berlin Ozone (BERLIOZ) experiment. Atmos. Chem. Phys., 6, 2091-2106.

Sandu, A, D.N. Daescu, G.R. Carmichael and Tianfeng Chai, 2005a: Adjoint sensitivity analysis of regional air quality models. J. of Comput. Phys., 204, Issue 1, 222-252.

Schmidt, H. and D. Martin, 2003: Adjoint sensitivity of episodic ozone in the Paris area to emissions on the continental scale. J. Geophys. Res., 108, 8561-8577, doi:10.1029/2001D001583.

Stavrakou, T. and J.F. Muller, 2006. Grid-based versus big region approach for inverting CO emissions using Measurement of Pollution in the Troposphere (MOPITT) data. J. Geophys. Res., 111, D15304, 2005JD006896, 2006.

Wang, K.Y., D.J. Lary, D.E. Shallcross, S.M. Hall and J.A. Pyle, 2001. A review on the use of the adjoint method in fourdimensional atmospheric chemistry data assimilation. Quart. J. of the Royal Met. Society, 127, 2181-2204.

Zhang, L, E.M. Constantinescu, A. Sandu, Y. Tang, T. Chai, G.R. Carmichael, D. Byun and E. Olaguer, 2008: An adjoint sensitivity analysis and 4D-Var data assimilation study of Texas air quality. Atmos. Environ., 42, 5787-5804.

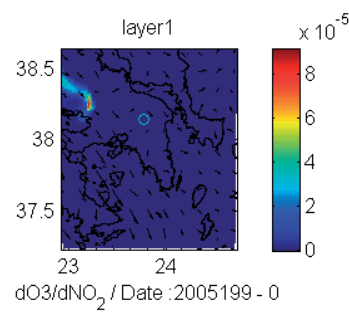

layer1

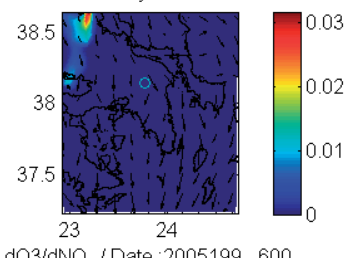

dO3/dNO $/$ / Date :2005199 - 600

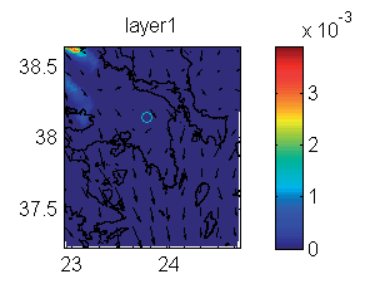

dO3/dNO $/$ / Date : 2005199 - 300

layer1

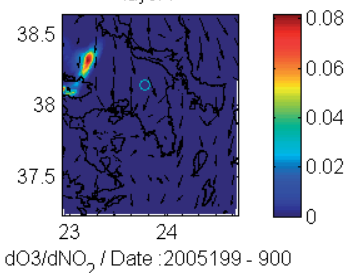

dO3/dNO 2 / Date :2005199 - 900

Figure 2. Sensitivity plots for $\mathrm{dO} 3 / \mathrm{dNO}_{2}$ every $3 \mathrm{~h}$ for receptor placed at Thrakomakedones area (o) at 18/7 - 12:00 GMT. 


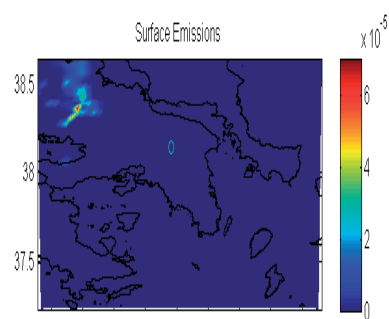

23222842362382424224424.8

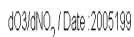

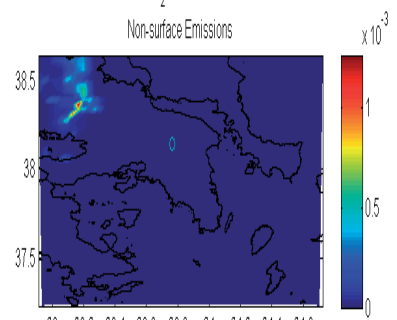

2323223423623824242244246

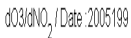

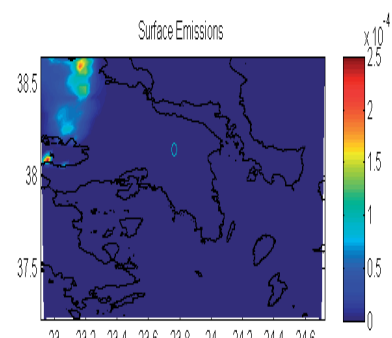

2323223423623824242244246

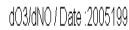

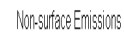

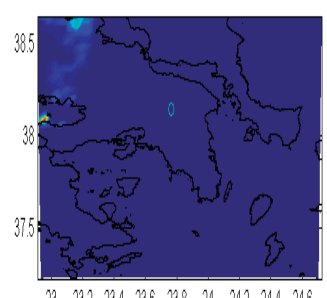

2323223423623824242244246

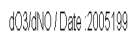

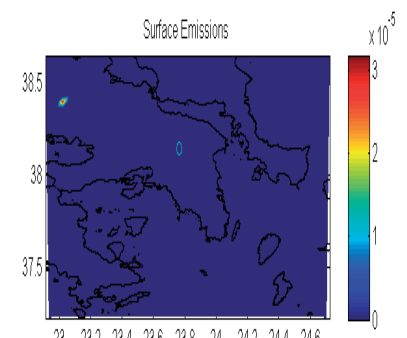

23 23223423623824242244246

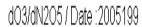

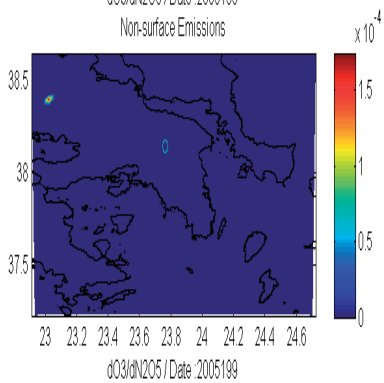

Figure 3. Sensitivity plots for $\mathrm{dO}_{3} / \mathrm{dNO}_{\mathrm{X}}$ emissions for receptor placed at Thrakomakedones area (o) at 18/7 - 12:00 GMT.
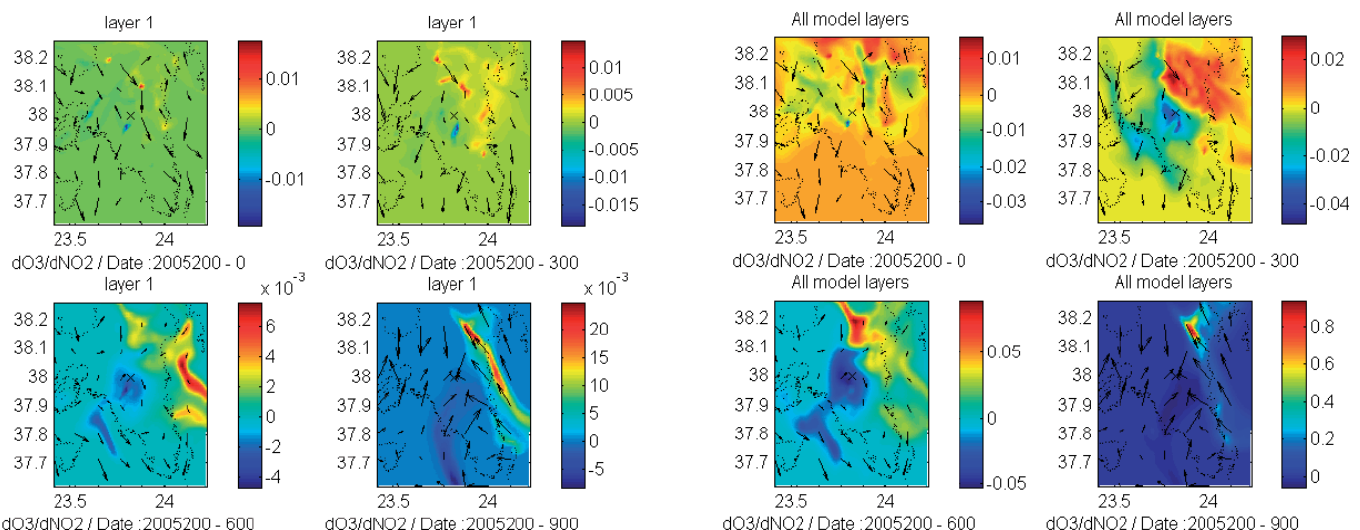

Figure 4a. Sensitivity plots for $\mathrm{dO}_{3} / \mathrm{dNO}_{2}$ every $3 \mathrm{~h}$ for receptor placed at Ag Paraskevi area at 19/7 - 12:00 GMT.
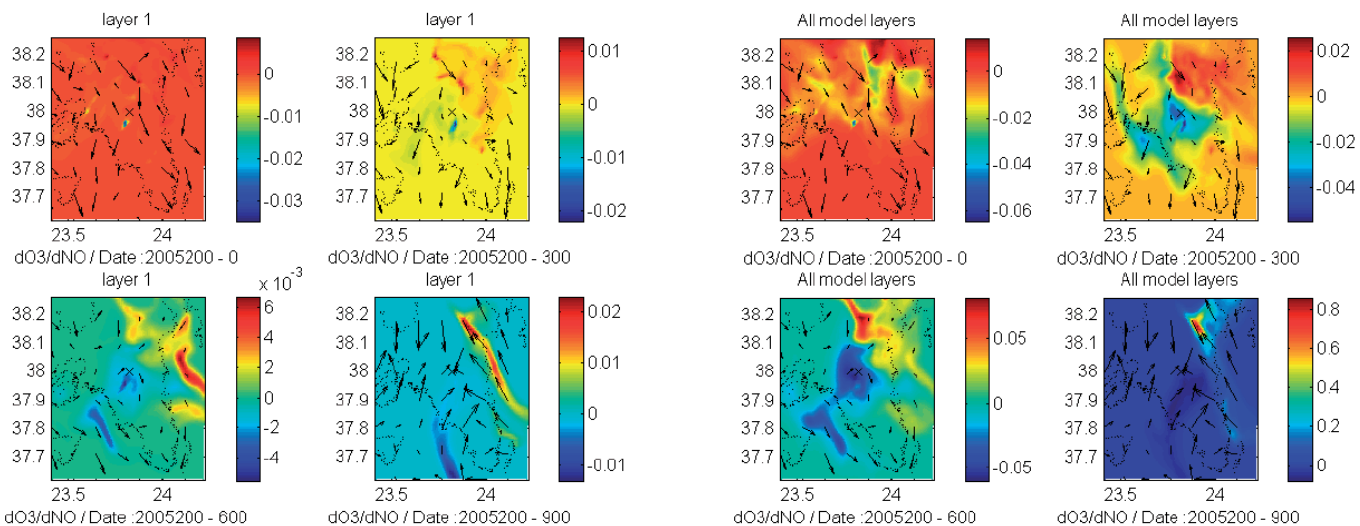

Figure 4b. Sensitivity plots for $\mathrm{dO}_{3} / \mathrm{dNO}$ every $3 \mathrm{~h}$ for receptor placed at Ag Paraskevi area at 19/7 - 12:00 GMT. 

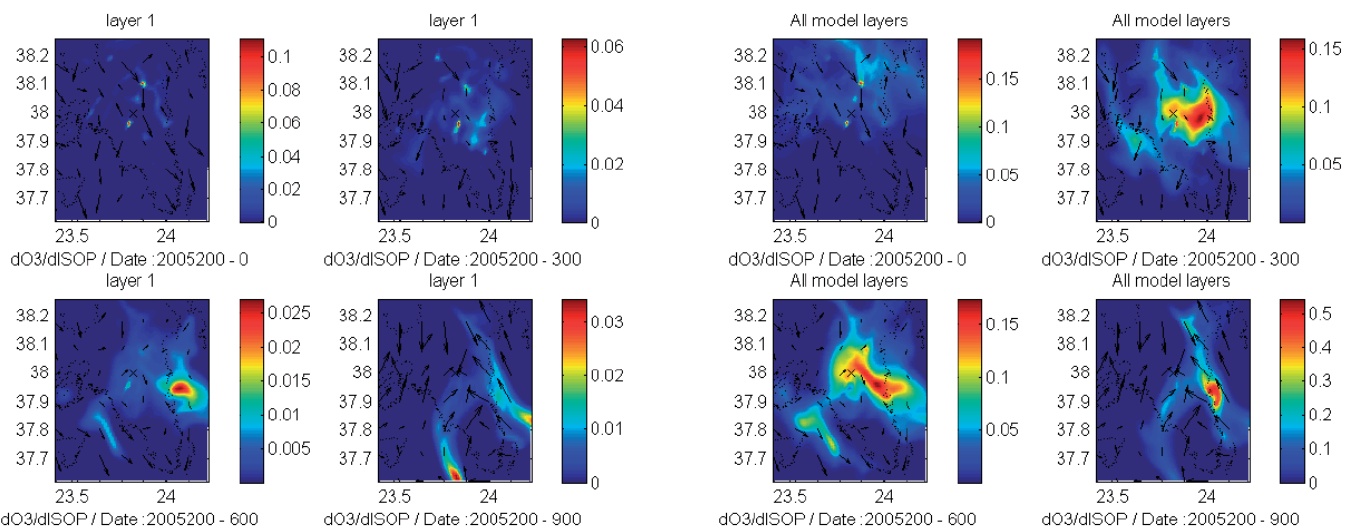

Figure 4c. Sensitivity plots for dO3/dISOP every $3 \mathrm{~h}$ for receptor placed at Ag Paraskevi area at 19/7 - 12:00 GMT.
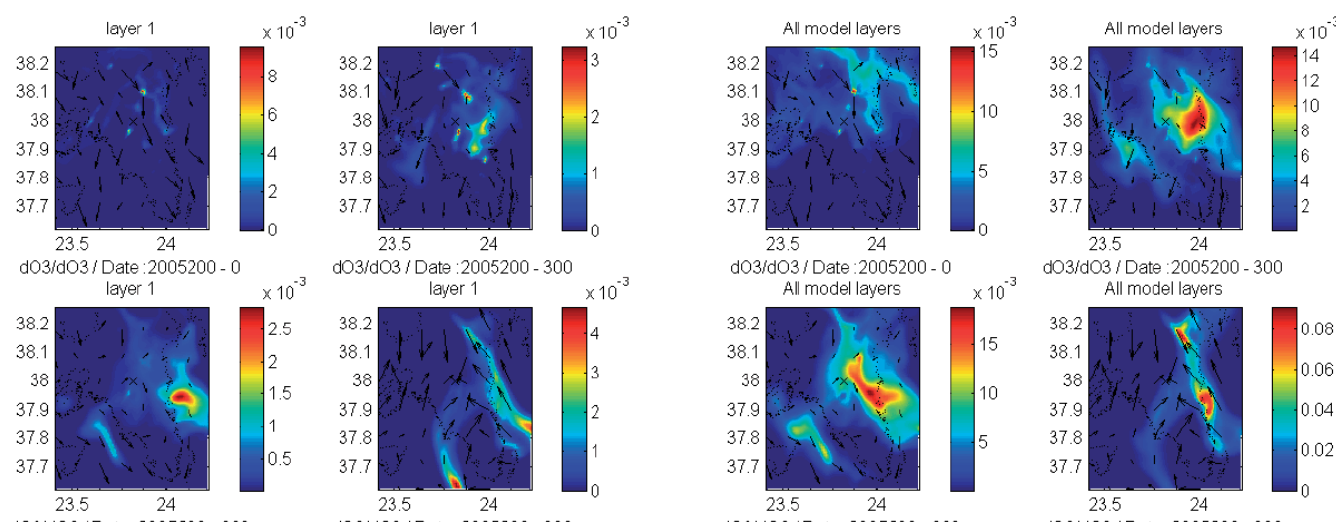

dO3/dO3/Date :2005200 - 900
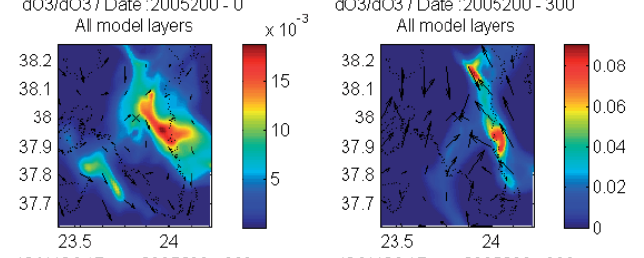

Figure 4d. Sensitivity plots for dO3/dO3 every $3 \mathrm{~h}$ for receptor placed at Ag Paraskevi area at 19/7 - 12:00 GMT.
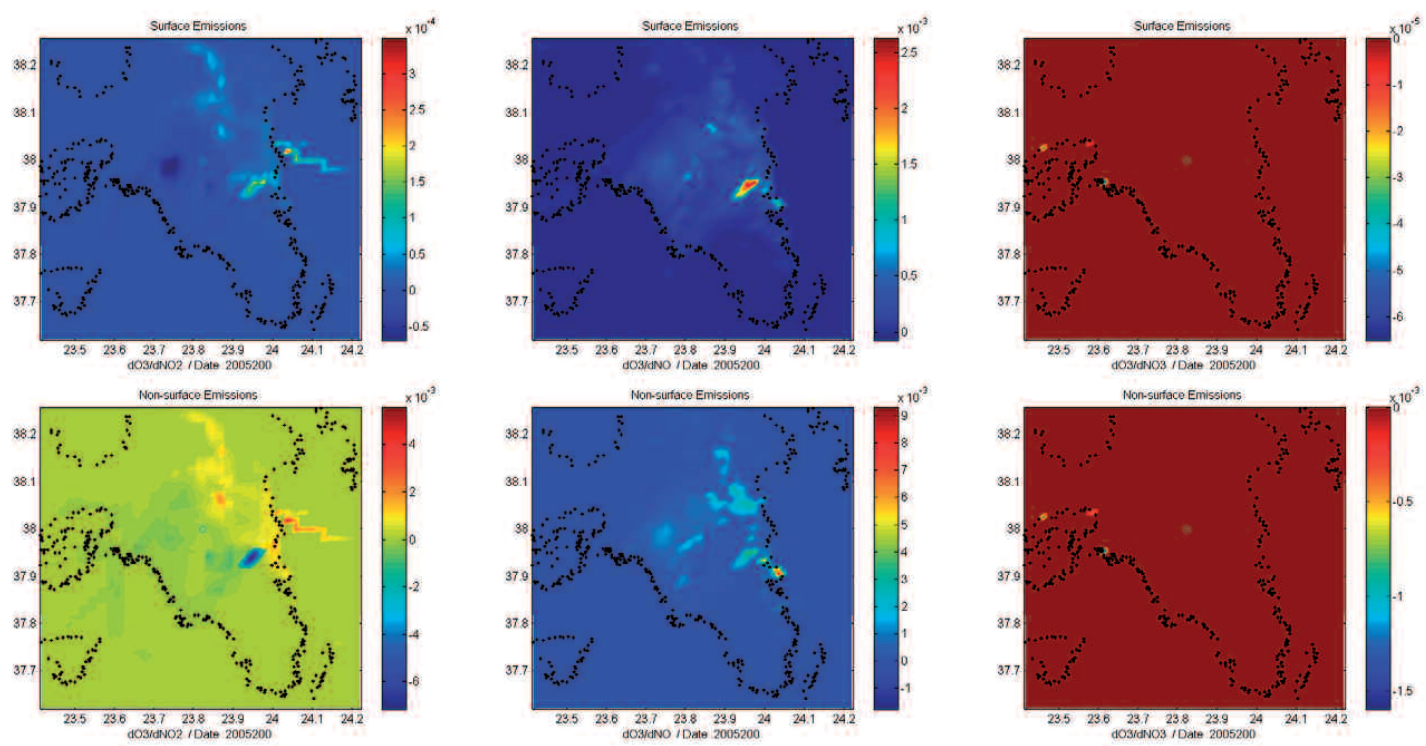

Figure 5. Sensitivity plots for $\mathrm{dO} / \mathrm{dNO}_{\mathrm{x}}$ emissions for receptor placed at Ag Paraskevi area at 19/7 - 12:00 GMT. 